\title{
In vitro evaluation of Cordyceps militaris as a potential radioprotective agent
}

\author{
MIN-HO JEONG ${ }^{1}$, YOU-SOO PARK ${ }^{2}$, DONG-HYEOK JEONG ${ }^{2}$, CHANG-GEUN LEE ${ }^{2}$, \\ JOONG-SUN KIM ${ }^{2}$, SU-JUNG OH ${ }^{2}$, SOO-KYUNG JEONG ${ }^{2}$, KWANGMO YANG ${ }^{2}$ and WOL-SOON JO ${ }^{2}$ \\ ${ }^{1}$ Department of Microbiology, Dong-A University College of Medicine; ${ }^{2}$ Research Center, \\ Dong Nam Institute of Radiological and Medical Sciences, Busan 619-953, Republic of Korea
}

Received April 29, 2014; Accepted August 6, 2014

DOI: $10.3892 / \mathrm{ijmm} .2014 .1901$

\begin{abstract}
Radiation is an important component of therapy for a wide range of malignant conditions. However, it triggers DNA damage and cell death in normal cells and results in adverse side-effects. Cordyceps militaris (C. militaris), a traditional medicinal mushroom, produces the bioactive compound, cordycepin (3'-deoxyadenosine) and has multiple pharmacological activities, such as antitumor, antimetastatic, antioxidant and immunomodulatory effects. The present study was undertaken to investigate whether CM-AE, an extract obtained from $C$. militaris exerts protective effects against radiation-induced DNA damage. The protective effects of CM-AE were compared with those of cordycepin. CM-AE effectively increased free radical scavenging activity and decreased radiation-induced plasmid DNA strand breaks in in vitro assays. CM-AE significantly inhibited the generation of reactive oxygen species (ROS) and cellular DNA damage in $2 \mathrm{~Gy}$ irradiated Chinese hamster ovary (CHO)-K1 cells. Moreover, treatment with CM-AE induced similar levels of phosphorylated $\mathrm{H} 2 \mathrm{AX}$ in the cells, which reflects the initial DNA double-strand breaks in the irradiated cells compared with the non-irradiated CHO-K1 cells. However, cordycepin did not show free radical scavenging activity and did not protect against radiation-induced plasmid DNA or cellular DNA damage. These results suggest that the free radical scavenging activity of CM-AE contributes towards its DNA radioprotective effects and that the protective effects of CM-AE are much more potent to those of cordycepin. The
\end{abstract}

Correspondence to: Dr Kwangmo Yang or Dr Wol-Soon Jo, Research Center, Dong Nam Institute of Radiological and Medical Sciences, Jwadong-gil 40, Jangan-eup, Gijang-gun, Busan 619-953, Republic of Korea

E-mail: kmyang@dirams.re.kr

E-mail: sailorjo@dirams.re.kr

Key words: Cordyceps militaris, cordycepin, free radical scavenging activity, reactive oxygen species, DNA damage, radioprotection data presented in this study may provide useful information for the screening of potent radioprotective materials.

\section{Introduction}

In recent years, radiation has gained tremendous value in the diagnosis and treatment of a number of malignancies and radiation in one form or another is now indispensble in virtually every branch of medicine. It has been used for more than a century in the treatment of cancer, since rapidly proliferating cancer cells are more sensitive than other tissue to DNA damage induced by radiation (1). However, radiotherapy uses high doses of ionizing radiation to kill cancer cells, which can cause damage to normal cells. The use of combination treatments, such as concomitant radiotherapy and chemotherapy also exacerbates the acute damage to normal tissue (2). In particular, surrounding normal tissues, such as lympho-haematopoietic tissue or the reproductive system are as susceptible to these debilitating reactions as targeted tumor cells due to their active replication (3). Thus, the development of radioprotective agents is crucial in clinical radiotherapy in order to obtain optimal tumor control and to protect normal tissues from potential radiation damage.

Exposure to a higher dose of ionizing radiation for cancer treatment leads to mortality in a mammalian system by multiple mechanisms, including direct DNA damage and indirect oxidative stress (4). Direct effects are the irreparable damage to critical targets within a cell, such as DNA. Indirect effects result from radiation interacting with other molecules in cells that are not critical targets, but are close enough to pass on damage, typically in the form of free radicals. As mammals are composed of roughly $80 \%$ water, indirect effects include the production of hydroxyl free radicals, which are potent oxidants capable of breaking chemical bonds and initiating lipid peroxidation in nano- to microsecond timeframes (5). These free radicals interact with critical macromolecules leading to DNA damage, which may be the most important factor in cell death (4-7). Although cells and tissues are equipped with endogenous enzymes [e.g., superoxide dismutase (SOD)] capable of detoxifying and removing water radiolysis products, when the production of these reactive oxygen species (ROS) increases following exposure to irradiation, the system is incapable of protecting the cells from the hazardous effects of free radicals $(6,7)$. 
A number of compounds have been tested to develop more effective or less toxic drugs to address the great clinical need for effective radioprotectant agents. Over the past decade, attention has been paid to natural compounds, which have lower toxicity than synthetic radioprotectors (8) as many synthetic compounds have many drawbacks, including high cost, side-effects and toxicity (9). Furthermore, it is well known that natural compounds have strong radical scavenging and antioxidant activity (8). Several plant extracts, herbal preparations and phytochemicals have been reported to exert radioprotective effects in in vitro and in vivo studies, and their radiation-protecting abilities have been attributed to their antioxidant and free-radical scavenging properties (10-13). However, few clinical trials for their efficacy in clinical use have been reported to date.

Cordyceps militaris ( $C$. militaris), the rare Chinese caterpillar fungus, has been used in traditional medicine to maintain health and to treat numerous diseases associated with the circulatory, respiratory, glandular and metabolic systems (14). It contains many types of phytochemicals, such as cordycepin, polysaccharides, ergosterol and mannitol, and due to its various physiological activities, it is now used for multiple medicinal purposes $(15,16)$. The important bioactive compound, cordycepin (3'-deoxyadenosine), a nucleoside analogue, is considered as a nucleic acid antibiotic that may inhibit the canceration of cells, contributing to the normalization of cancer cells as one of the constituents of gene DNA $(17,18)$. A number of studies have demonstrated that the extracts of $C$. militaris have various pharmacological actions, such as anti-angiogenetic (19), anti-inflammatory (20), antioxidant $(21,22)$, antitumor (23-25) and immunomodulatory activities (26). Although $C$. militaris extract and cordycepin have been extensively tested for their pharmacological and biological effects, the radioprotective effects of $C$. militaris extract remain unclear.

In the present study, we investigated the protective effects of the extract of $C$. militaris against radiation-induced DNA damage in Chinese hamster ovary (CHO)-K1 cells. Our data suggest that $C$. militaris has potential radioprotective activity.

\section{Materials and methods}

Chemicals and reagents. Cordycepin, 1,1diphenyl-2-picryl hydrazyl (DPPH), nitroblue tetrazolium (NBT), phosphatebuffered saline (PBS), 3-(4,5-dimethyl-2-yl)-2,5-diphenyl-2II tetrazolium bromide (MTT), dimethyl sulfoxide (DMSO) and other chemical reagents were purchased from Sigma (St. Louis, MO, USA).

Sample preparation. C. militaris used in the present study was supplied by Chungwon-Industrial Farm (Busan, Korea) which had constructed the $C$. militaris JLM 0636 strain by single spore fusion of various strains of $C$. militaris. For the preparation of the extract from $C$. militaris JLM 0636 (CM-AE), the powder of dried fruiting bodies was extracted with distilled deionized water for $3 \mathrm{~h}$ at $121^{\circ} \mathrm{C}$, the insoluble materials were removed by centrifugation at $10,000 \mathrm{x} \mathrm{g}$ for $30 \mathrm{~min}$ and filtration was carried out using a $0.45-\mu \mathrm{m}$ membrane filter. The CM-AE was then lyophilized using a VirTis freeze dryer (VirTis Co., Gardiner, NY, USA) for use in later experiments. The cordycepin content in CM-AE was analyzed by high performance liquid chromatagraphy (Perkin-Elmer 200 series system; Perkin-Elmer, Waltham, MA, USA) in our previous study (26). Cordycepin was used as the control compound.

Free radical scavenging activity of $C M-A E$. The following parameters were assayed to determine the free radical scavenging activity of CM-AE. DPPH radical scavenging was determined by the method of von Gadow and Hansmann (27) with some modifications. Briefly, $10 \mu \mathrm{l}$ of various concentrations of CM-AE and cordycepin (diluted to final concentrations of $31.3,62.5,125,250$ and $500 \mu \mathrm{g} / \mathrm{ml}$ ) were mixed with $190 \mu \mathrm{l}$ of DPPH in ethanol (final concentration $0.1 \mathrm{mM}$ ) in wells of a 96-well plate. The plate was kept in the dark for $10 \mathrm{~min}$, and the absorbance of the solution was measured at $517 \mathrm{~nm}$ using a microplate reader (VersaMax; Molecular Devices, Sunnyvale, CA, USA). Superoxide radical scavenging activity was assessed by the NBT reduction method of McCord and Fridovich (28) with some modifications. The reaction mixture contained $134 \mu \mathrm{l}$ of buffer (50 mM KH $\left.\mathrm{KH}_{4}, \mathrm{pH} 7.4\right), 2 \mu \mathrm{l}$ of $100 \mathrm{mM} \mathrm{Na}{ }_{2}$ EDTA, $20 \mu \mathrm{l}$ of $3 \mathrm{mM}$ hypoxanthine, $2 \mu \mathrm{l}$ of $10 \mathrm{mM}$ NBT, and $10 \mu \mathrm{l}$ of various concentrations of CM-AE and cordycepin. The absorbance of the samples was measured immediately following the addition of $32 \mu \mathrm{l}$ of xanthine oxidase (1 unit/10 $\mathrm{ml}$ buffer) at $540 \mathrm{~nm}$ using a microplate reader. The plate was kept in the dark for $10 \mathrm{~min}$, and absorbance was measured again at $540 \mathrm{~nm}$. Hydroxyl radical scavenging activity was measured using the OxiSelect ${ }^{\mathrm{TM}}$ HORAC Activity Assay kit (Cell Biolabs, San Diego, CA, USA). This assay is based on the oxidation-mediated quenching of a fluorescent probe by hydroxyl radicals produced by a hydroxyl radical initiator and Fenton's reagent.

Estimation of plasmid pSK DNA damage. A $5.5 \mathrm{~kb}$ length of plasmid pSK was transformed in E. coli and purified using an EndoFree Plasmid Maxi kit (Qiagen, Valencia, CA, USA). The pSK DNA $(0.5 \mu \mathrm{g})$ in PBS was exposed to 5 Gy-radiation in the presence and absence of CM-AE and cordycepin at various concentrations. Following irradiation, the DNA was electrophoresed on a $1 \%$ agarose gel in $0.08 \mathrm{M}$ Tris borate/0.2 mM EDTA buffer ( $\mathrm{pH}$ 8.3). The bands of supercoiled DNA (SC) and open circular DNA or broken DNA (OC) were visualized with SYBR Safe DNA gel staining (Invitrogen, Carlsbad, CA, USA) under UV light, and quantified by scanning and densitometric measurements using BIO-1D analysis software (Vilber Lourmat, Marne-la-Vallée, France). DNA lesions were expressed as a density ratio of the OC form.

$\gamma$-irradiation. $\gamma$-irradiation by ${ }^{137} \mathrm{Cs}$ was carried out using a Biobeam 8000 (Gamma-Service Medical GmbH, Leipzig, Germany) irradiator with a dose rate of $1.88 \mathrm{~Gy} / \mathrm{min}$.

Cell culture. The Chinese hamster ovary cell line, CHO-K1, was obtained from the American Type Tissue Collection (ATCC, Manassas, VA, USA). The CHO-K1 cells were cultured in F-12 nutrient mixtures (Ham's F-12; Welgene, Daegu, Korea) supplemented with $10 \%$ fetal bovine serum (FBS; HyClone, Logan, UT, USA). The cells were maintained at $37^{\circ} \mathrm{C}$ in a humidified atmosphere with $5 \% \mathrm{CO}_{2}$. 
Cell viability assay. The number of viable cells was determined by the ability of mitochondria to convert MTT to formazan dye. The CHO-K1 cells were cultured overnight in 96 -well plates, at a density of $2 \times 10^{4}$ cells $/ 200 \mu 1$ in each well. The following day, the cells were co-incubated with various concentrations of CM-AE and cordycepin for $24 \mathrm{~h}$. Following incubation, the medium was removed, and the cells were supplemented with $10 \mu \mathrm{l}$ of $10 \mathrm{mg} / \mathrm{ml} \mathrm{MTT}$ in each well. Following a further $4 \mathrm{~h}$ of incubation at $37^{\circ} \mathrm{C}$ in a humidified $5 \% \mathrm{CO}_{2}$ atmosphere, the MTT was removed, and the cells were lysed with $150 \mu \mathrm{l}$ DMSO. The absorbance was measured at $550 \mathrm{~nm}$ using a microplate reader.

2',7'-Dichlorofluorescein (DCFH) assay. The CHO-K1 cells were cultured in 96 -well plates, at a density of $3 \times 10^{4}$ cells $/ 200 \mu 1$ in each well and treated with various concentrations of $\mathrm{CM}-\mathrm{AE}$ and cordycepin at $37^{\circ} \mathrm{C}$ in a humidified atmosphere with $5 \% \mathrm{CO}_{2}$ for $1 \mathrm{~h}$. The cells were supplemented with $25 \mu \mathrm{M}$ 2',7'-dichlorfluorescein-diacetate (DCFH-DA; Sigma-Aldrich) solution and were immediately exposed to $2 \mathrm{~Gy}$ of ${ }^{137} \mathrm{Cs}$ $\gamma$-radiation. Following irradiation, the cells were incubated at $37^{\circ} \mathrm{C}$ for $10 \mathrm{~min}$ and the fluorescence intensity of DCFH-DA was measured using Paradigm ${ }^{\mathrm{TM}}$ Detection Platform and Multimode Analysis Software version 3.1.0.1 (Beckman Coulter, Fullerton, CA, USA). The excitation and emission wavelengths were 480 and $530 \mathrm{~nm}$, respectively.

Comet assay. The CHO-K1 cells were cultured overnight in 6 -well plates, at a density of $2 \times 10^{5}$ cells $/ 3 \mathrm{ml}$ in each well. The following day, the cells were treated with various concentrations of CM-AE and cordycepin for $15 \mathrm{~min}$, exposed to 2 Gy of ${ }^{137} \mathrm{Cs} \gamma$-radiation, and incubated at $37^{\circ} \mathrm{C}$ in a humidified atmosphere with $5 \% \mathrm{CO}_{2}$ for $15 \mathrm{~min}$. The cells were collected and mixed with low melting point agarose at $37^{\circ} \mathrm{C}$. This mixture was placed on the top of the previous layer of $0.5 \%$ normal melting point agarose on a slide covered with a coverslip, and returned to $4^{\circ} \mathrm{C}$ until solid. The coverslip was gently removed and some NMP agarose was added to the slide. The slide was covered again with a coverslip and placed at $4^{\circ} \mathrm{C}$ until the mixture was solid. The slide was placed in chilled lysis buffer (100 mM EDTA, 2.5 M sodium chloride, $10 \mathrm{mM}$ Trizma base and $1 \%$ N-lauroylsarcosinate, adjusted to $\mathrm{pH} 10.0$, with $1 \%$ Triton $\mathrm{X}-100)$ and unwinding buffer $(1 \mathrm{mM}$ EDTA and $300 \mathrm{mM}$ sodium hydroxide, $\mathrm{pH}>13$ ), respectively, and subjected to electrophoresis. Thereafter, the slides were gently washed with $0.4 \mathrm{M}$ Tris buffer, stained with GelGreen DNA dye (Biotium, Inc., Hayward, CA, USA), and analyzed under a fluorescence microscope (Carl Zeiss, Oberkochen, Germany). The images were captured, and a minimum of 100 comets per slide, in triplicate for a group, were analyzed using Metafer 4 software (MetaSystems; Carl Zeiss) which yields the percentage DNA in the tail, tail length, tail moment (TM) and olive tail moment (OTM) directly. The parameter TM is the product of the tail length and percentage DNA in the tail, and the OTM is the product of the distance between the center of the head and the center of the tail and percentage DNA in the tail (29).

Immunofluorescence staining of phoshphorylated H2AX. The CHO-K1 cells were cultured overnight in 6-well plates, at a density of $3 \times 10^{5}$ cells $/ 3 \mathrm{ml}$ in each well. The following day, the cells were treated with various concentrations of CM-AE and cordycepin for $15 \mathrm{~min}$, exposed to $2 \mathrm{~Gy}$ of ${ }^{137} \mathrm{Cs} \gamma$-radiation and incubated at $37^{\circ} \mathrm{C}$ in a humidified atmosphere with $5 \%$ $\mathrm{CO}_{2}$ for $45 \mathrm{~min}$. The cells were cytocentrifuged on slides, fixed with $4 \%$ formaldehyde (Biosesang, Seoul, Korea), permeabilized for $10 \mathrm{~min}$ on ice in $0.2 \%$ Triton X-100 in PBS, and washed thoroughly with PBS. The slides were then incubated with anti-phosphorylated histone H2AX (serine 139) antibody (Abcam, Cambridge, MA, USA) in PBS at room temperature for $1 \mathrm{~h}$. The primary antibodies were washed with PBS, and Texas Red Goat anti-mouse IgG secondary antibody (Vector Laboratories, Inc., Burlingame, CA, USA) was added. The slides were incubated at room temperature for $1 \mathrm{~h}$, washed with PBS, and incubated at room temperature with $4 \mu \mathrm{g} / \mathrm{ml}$ Hoechst 33342 (4',6-diamidino-2-phenylindole; Invitrogen) for $15 \mathrm{~min}$. All sldies were mounted with $0.05 \mathrm{ml}$ PBS containing $10 \%$ glycerol (Wako Pure Chemical Industries, Ltd., Osaka, Japan) and were examined using a Zeiss fluorescence microscope. The red intensity of the phospho-H2AX signal on the digitized images was analyzed using AxioVision Rel. 4.8 software (Carl Zeiss).

Statistical analysis. All data are expressed as the means \pm standard deviation. Statistical significance was tested using the Statistical Package for the Social Sciences statistical software for Windows, version 18.0 (SPSS, Inc., Chicago, IL, USA). Data were tested for normality using the Kolmogorov-Smirnov test and for homogeneity of variance using Levene's test, prior to any statistical analysis. The data were normally distributed and the variances were homogeneous. Therefore, significant differences between 2 groups were evaluated using the Student's t-test and significant differences between more than 2 groups were evaluated by one-way analysis of variance with Dunnett's post hoc test for multiple comparisons. A value of $\mathrm{P}<0.05$ was considered to indicate a statistically significant difference.

\section{Results}

Effect of CM-AE on free radical scavenging activity. The concentration of cordycepin contained in the JLM 0636 strain of $C$. militaris was $7.42 \mathrm{mg} / \mathrm{g}$ (dry weight) as shown in our previous study (26), which was calculated from the peak area shown in the standard curve of commercial cordycepin. To investigate the free radical scavenging activity of cordycepinenriched CM-AE, we performed DPPH assay, NBT/XO assay, and the oxidation of a fluorescent probe by hydroxyl radicals, and compared the results with those of cordycepin as the control compound. The stable free radical scavenging activity of DPPH with characteristic absorption at $517 \mathrm{~nm}$ was significantly increased by CM-AE $(\mathrm{P}<0.05)$ (Fig. 1A). CM-AE also inhibited the generation of superoxide radicals and hydroxyl radical production in a concentration-dependent manner, as shown by the increased superoxide radical scavenging activity (Fig. 1B and C). However, cordycepin showed little free radical scavenging activity as regards DPPH radicals, superoxide radicals and hydroxyl radicals at the tested concentrations (Fig. 1).

Effect of CM-AE on $\gamma$-radiation-induced DNA damage in plasmid $p S K$. To determine the DNA protecting activity of 

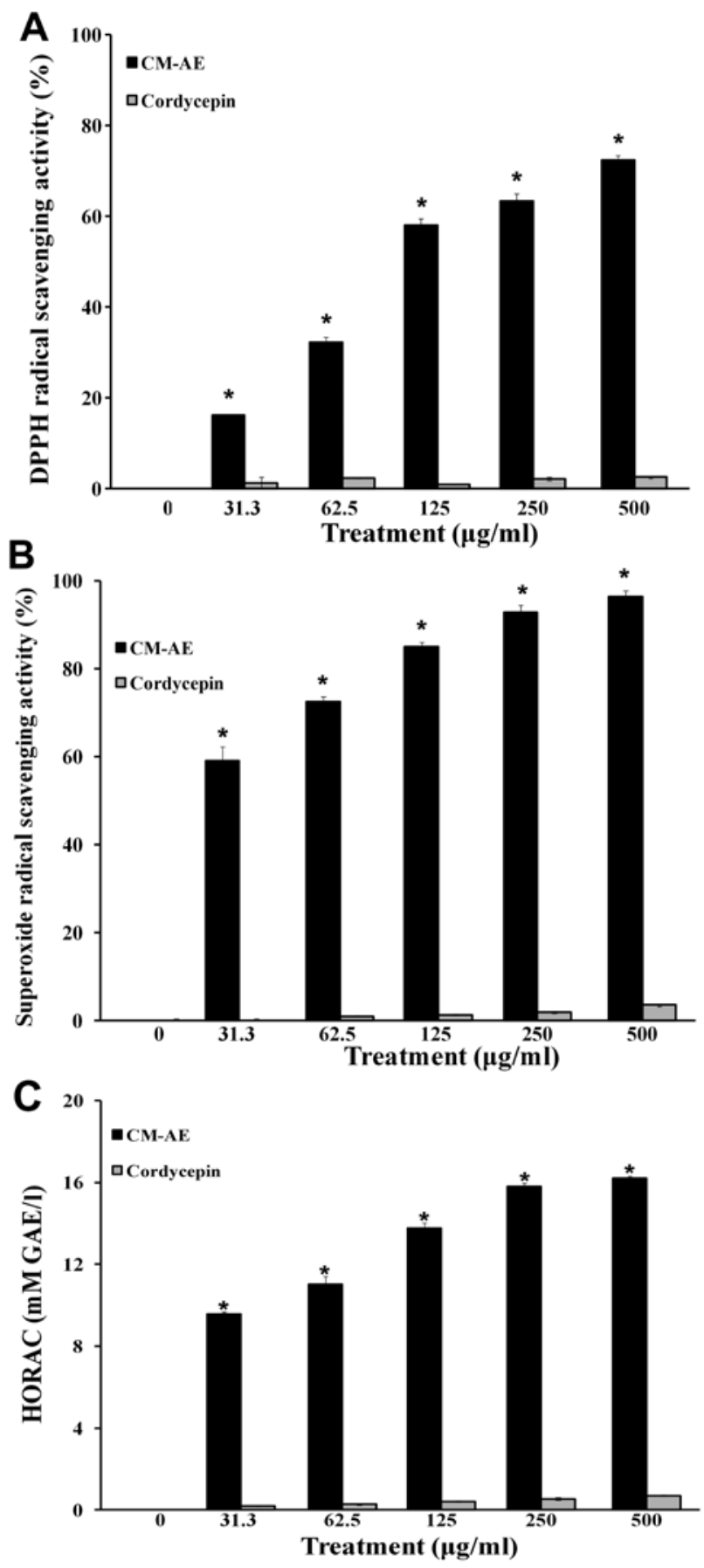

Figure 1. Free radical scavenging activity of CM-AE. (A) DPPH radical scavenging activity was determined by the reduction of DPPH, and (B) superoxide radical scavenging ability was measured by the level of nitroblue tetrazolium (NBT) reduction when cells were incubated with the indicated concentrations of CM-AE. The percentage inhibition of the DPPH free radical and superoxide radicals was calculated as a measure of radical scavenging activity of $\mathrm{CM}-\mathrm{AE}$ (C) Hydroxyl radical (HORAC) scavenging activity of CM-AE was measured using an HORAC activity assay kit. The antioxidant capacity of CM-AE was calculated on the basis of the area under the fluorescence decay curve compared with an antioxidant standard curve obtained with gallic acid (for HORAC). Cordycepin was used as the control compound. Data are the means \pm SD of triplicate samples of 3 independent experiments. ${ }^{*} \mathrm{P}<0.05$ as compared to the untreated control.

CM-AE in vitro, we measured plasmid pSK DNA damage with 5 Gy of $\gamma$-irradiation in the absence or prescence CM-AE and compared the results with those of cordycepin. The expo-
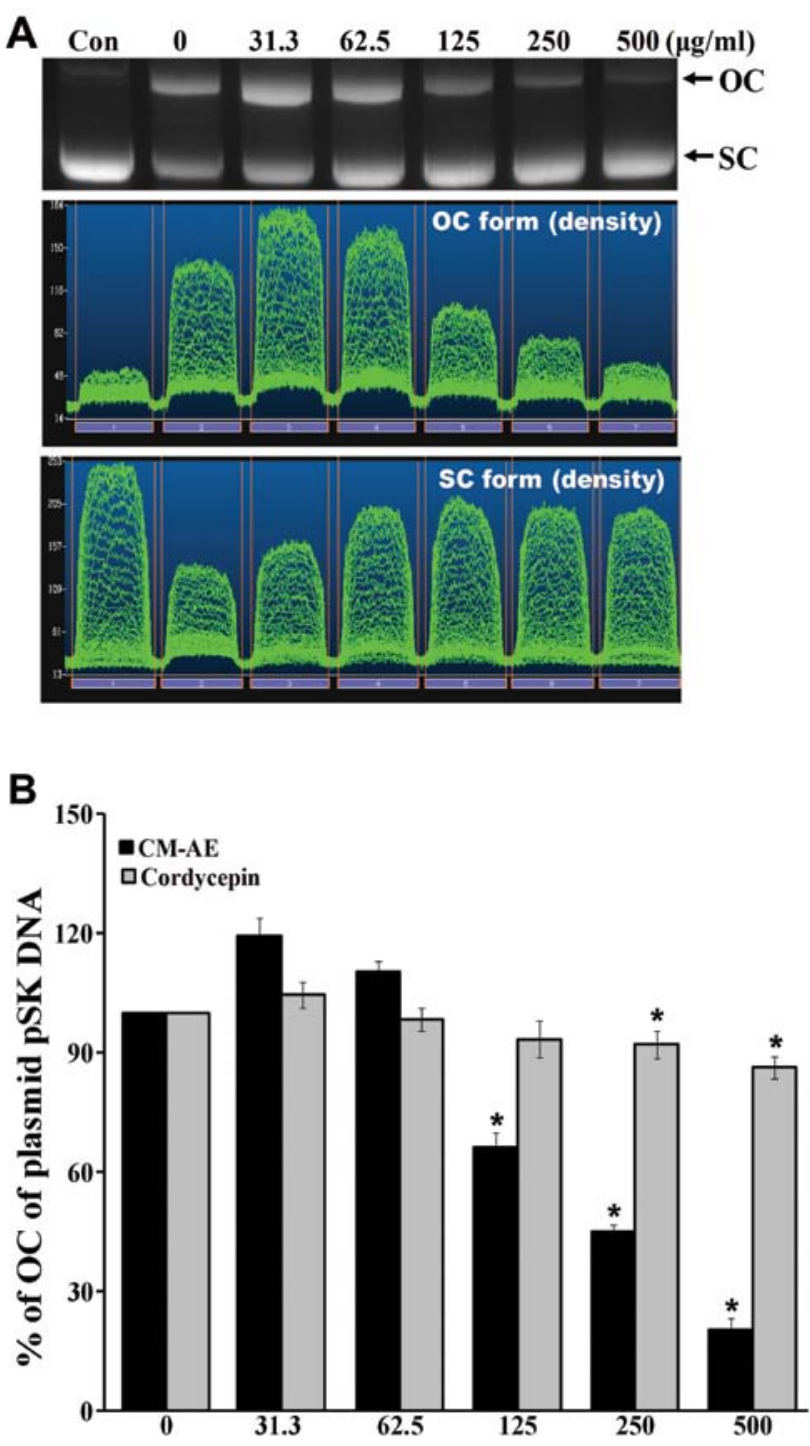

Figure 2. Effects of CM-AE on ${ }^{137} \mathrm{Cs} \gamma$-radiation-induced DNA strand breaks in plasmid pSK DNA. The plasmid DNA was exposed to $5 \mathrm{~Gy} \gamma$-radiation in the presence of various concentrations of CM-AE. Following irradiation, the DNA was electrophoresed in a $1 \%$ agarose gel and DNA damage was analyzed using a gel documentation system. Cordycepin was used as the control compound. (A) Agarose gel electrophoresis pattern of pSK DNA exposed to 5 Gy. (B) Quantification of plasmid DNA strand breaks were expressed by the density ratio (irradiated pSK DNA/non-irradiated pSK DNA) of the open circular (OC) form of pSK DNA. Data are the means \pm SD of triplicate samples of 3 independent experiments. $\mathrm{P}<0.05$ as compared to irradiation alone. Con, control; SC, supercoiled form of DNA.

sure of plasmid pSK DNA to ${ }^{137} \mathrm{Cs} \gamma$-radiation resulted in the production of strand breaks in which the supercoiled covalently closed circular (SC) form of DNA was converted to the open circular or linear forms (OC) in a radiation dose-dependent manner, as demonstrated in a previous study of ours (30). Hence, this plasmid DNA relaxation assay with pSK DNA was thought to be a useful tool for the study of the radioprotective efficacy of CM-AE against direct DNA damage. The data on the effects of various concentrations of $\mathrm{CM}-\mathrm{AE}$ on radiationinduced disappearance of the OC form of plasmid pSK DNA are presented in Fig. 2. There was a concentration-dependent inhibition of the disappearance of the OC form of plasmid 

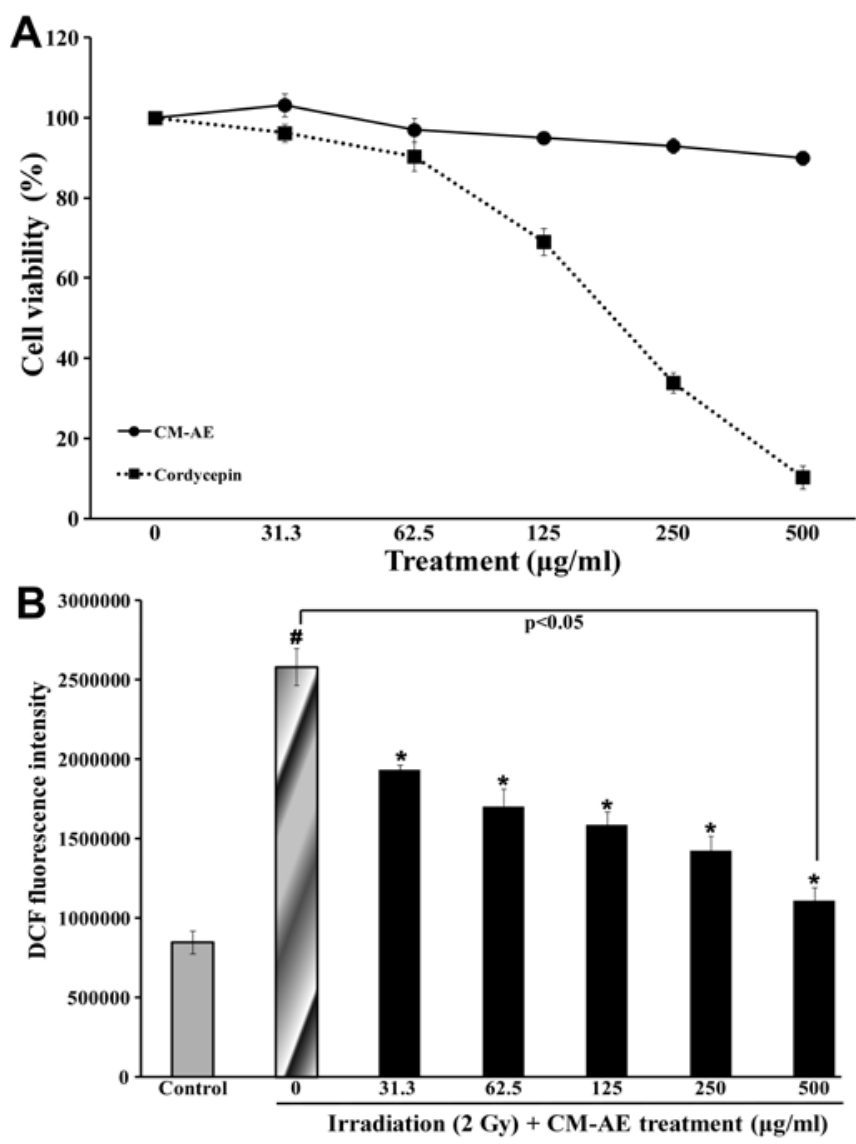

Figure 3. Effects of reactive oxygen species (ROS) production by CM-AE in ${ }^{137} \mathrm{Cs} \gamma$-radiation0exposed CHO-K1 cells. (A) The cells were treated with the indicated concentrations of CM-AE for $24 \mathrm{~h}$. Cell viability was determined by MTT assay. Each percentage value in the treated cells was calculated with respect to that in the untreated control. Results are expressed as percentages of the control. (B) The cells were treated with the indicated concentrations of CM-AE for $1 \mathrm{~h}$ and $25 \mu \mathrm{M}$ DCFH-DA was added. The cells were immediately exposed to $2 \mathrm{~Gy}$ of ${ }^{137} \mathrm{Cs} \gamma$-radiation and incubated for $10 \mathrm{~min}$. ROS production was measured by DCFH assay. The results are expressed as the intensity of DCFH fluorescence. Data are the means \pm SD of triplicate samples of 3 independent experiments. ${ }^{*} \mathrm{P}<0.05$ as compared to the non-irradiated control and ${ }^{*} \mathrm{P}<0.05$ compared to irradiation alone.

DNA following exposure to $5 \mathrm{~Gy}$ of $\gamma$-radiation at 125, 250 and $500 \mu \mathrm{g} / \mathrm{ml}$. There was significant reduction of the OC form of plasmid DNA following treatment with cordycepin at 250 and $500 \mu \mathrm{g} / \mathrm{ml}$; however, the inhibitory effect was low when it was compared to the effect produced by $\mathrm{CM}-\mathrm{AE}(\mathrm{P}<0.05$; Fig. $2 \mathrm{~B})$.

Effect of CM-AE on cellular ROS production in irradiated CHO-K1 cells. To evaluate the effect of CM-AE on cellular ROS production, radiation-exposed $\mathrm{CHO}-\mathrm{K} 1$ cells were used. The experimental doses of CM-AE and cordycepin were determined as follows: the viability of the CHO-K1 cells was measured by MTT assay in the presence of CM-AE or cordycepin. CM-AE retained the viability of the CHO-K1 cells at $90 \%$ at a dose of up to $500 \mu \mathrm{g} / \mathrm{ml}$. However, cordycepin showed cytotoxicity in dose-dependent manner in the CHO-K1 cells (Fig. 3A). When irradiated with 2 Gy of ${ }^{137} \mathrm{Cs}$ $\gamma$-radiation, ROS production determined as by DCFH-DA assay was approximately 3 -fold greater than that in the nonirradiated $\mathrm{CHO}-\mathrm{K} 1$ cells (Fig. 3B). CM-AE significantly reduced ROS production in the irradiated $\mathrm{CHO}-\mathrm{K} 1$ cells in a dose-dependent manner (Fig. 3B); however, little difference was observed in the production of ROS following treatment with cordycepin compared to the irradiated cells at the tested concentration (data not shown).

Effect of CM-AE on cellular DNA damage in irradiated CHO-Kl cells. To demonstrate the protective effects of $\mathrm{CM}-\mathrm{AE}$ on cellular DNA damage, radiation-exposed CHO-K1 cells were used. We performed alkaline single-cell gel electrophoresis (comet assay) and immunefluorescence staining of phoshphorylated H2AX. As shown Fig. 4, there was a significant increase in comet parameters on DNA damage, such as percentage DNA in the tail, the tail length, tail moment, and olive tail moment in the irradiated $\mathrm{CHO}-\mathrm{K} 1$ cells compared to the non-irradiated cells. The presence of CM-AE during irradiation reduced these parameters in a dose-dependent manner in the CHO-K1 cells (Fig. 4). To verify the protective effect of CM-AE against cellular DNA double-strand breaks following irradiation, the number of $\gamma-\mathrm{H} 2 \mathrm{AX}$ foci was also measured in the CHO-K1 cells. As shown in Fig. 5, a greater number of red phosphorylated $\mathrm{H} 2 \mathrm{AX}$ foci were clearly observed in the nucleus following irradiation compared to the non-irradiated cells. Similarly, CM-AE reduced the number of positive cells with $\gamma$-H2AX foci in the CHO-K1 cells in a dose-dependent manner (Fig. 5). However, there was no reduction in cellular DNA damage follwing treatment with cordycepin, as shown by comet assay and immunefluorescence staining $(\gamma-\mathrm{H} 2 \mathrm{AX}$ foci) compared to the irradiated cells at tested concentration (data not shown).

\section{Discussion}

It is well known that most of the damage induced by radiation in living cells is due to the generation of aqueous free radicals. In particular, water, the most abundant intracellular material, decomposes following exposure to ionizing radiation and generates primary hydroxyl radicals $(\bullet \mathrm{OH})$ and secondary superoxide radicals, which leads to serious cell damage from DNA strand breaks (31). Hence, compounds that protect DNA breaks from ionizing radiation-induced free radicals have considerable potential as radioprotectors. Recent studies on the development of radioprotectors have focused on searching for effective and non-toxic compounds with herbal preparation. Herbal products have various pharmacological properties and have long been used for the treatment of various diseases. Therefore, the screening of herbal drugs offers a major focus for new drug discovery. In this regard, attention over the past 15 years has shifted towards the evaluation of herbal products as radioprotectors, due to their efficacy and low toxicity. The suggested radioprotective efficacy of herbal extracts is a result of the fact that they contain a large number of active constituents which have antioxidant activity (32).

The pharmacological effects of several medicinal mushrooms are related to their free radical scavenging properties, and $C$. militaris is one of the most important medicinal mushrooms (33). C. militaris extracts have been reported to have antioxidant properties $(34,35)$. It has been reported that the water-soluble crude extract of $C$. militaris exhibits scavenging activity towards hydroxyl radicals (35). In addition, 

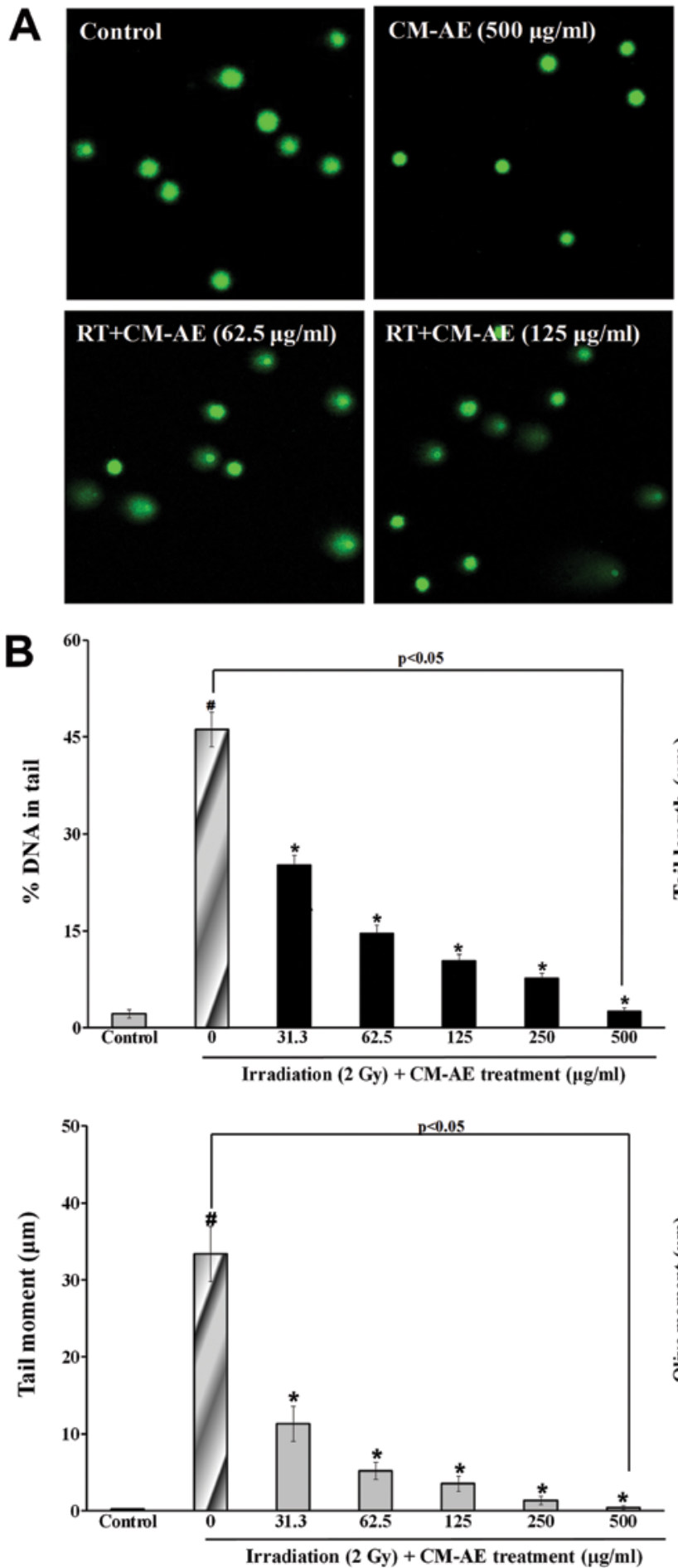
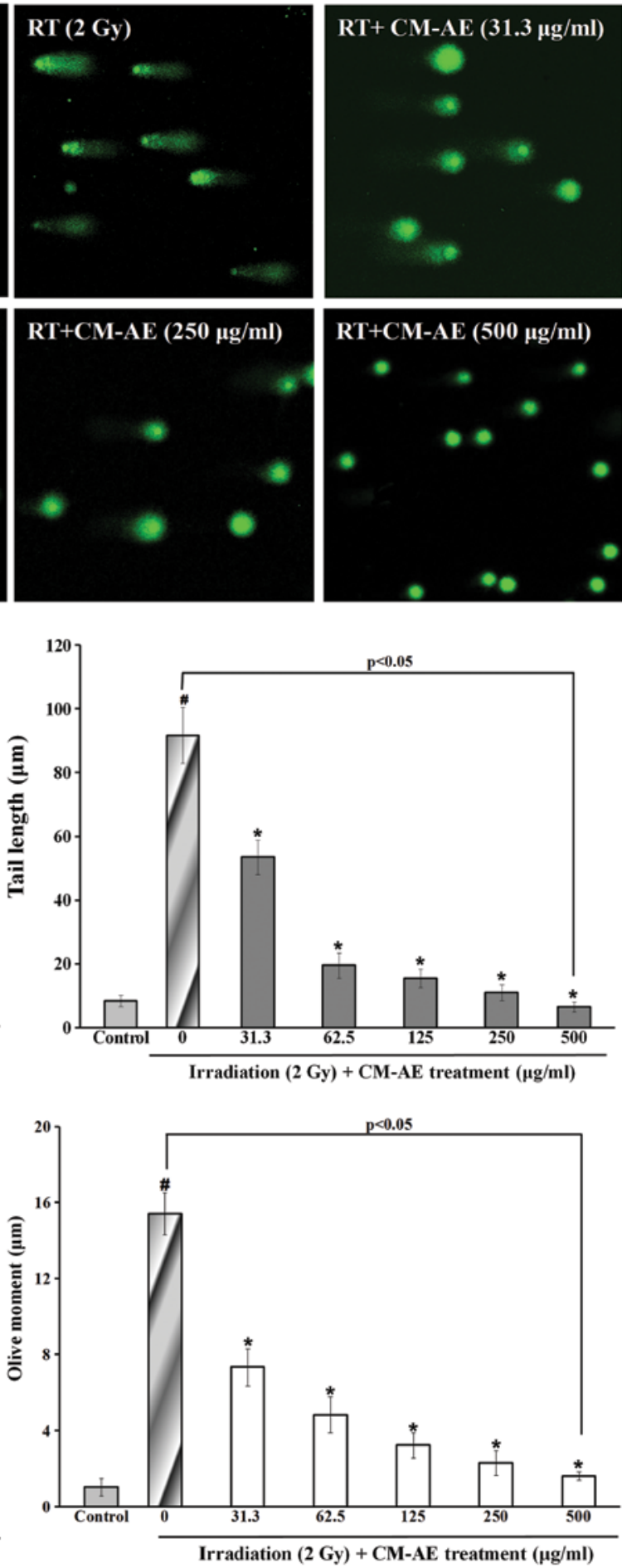

Figure 4. Effects of CM-AE on DNA damage in irradiated CHO-K1 cells. The cells were pre-treated with the indicated concentrations of CM-AE for 15 min prior to irradiation with $2 \mathrm{~Gy}$. Subsequently, the comet assay was performed after $15 \mathrm{~min}$ of irradiation. (A) Photomicrographs of comet length and (B) the representative comet parameters (percentage DNA in the tail, tail length, tail moment and olive tail moment) presented for each condition. A minimum of 100 cells were analyzed using Metafer 4 software, and data are the means \pm SD of triplicate samples of 3 independent experiments. ${ }^{.} \mathrm{P}<0.05$ as compared to the non-irradiated control and ${ }^{*} \mathrm{P}<0.05$ compared to irradiation alone.RT, radiation.

the protective effects of $C$. militaris against oxidative damage have been compared, and the free radical scavenging ability of $C$. militaris has been shown to reduce the oxidative damage of biomolecules (36). The present study demonstrated that CM-AE obtained from the cordycepin-enriched JLM 0636 strain of $C$. militaris effectively scavenged in vitro DPPH radi- cals, superoxide radicals and hydroxyl radicals. Furthermore, the protective effects of CM-AE against plasmid DNA damage following irradiation, such as DNA strand breaks in vitro were demonstrated by quantifying the amount of DNA in both nicked circular and supercoiled forms. However, there was little increase in the free radical scavenging activity or the 

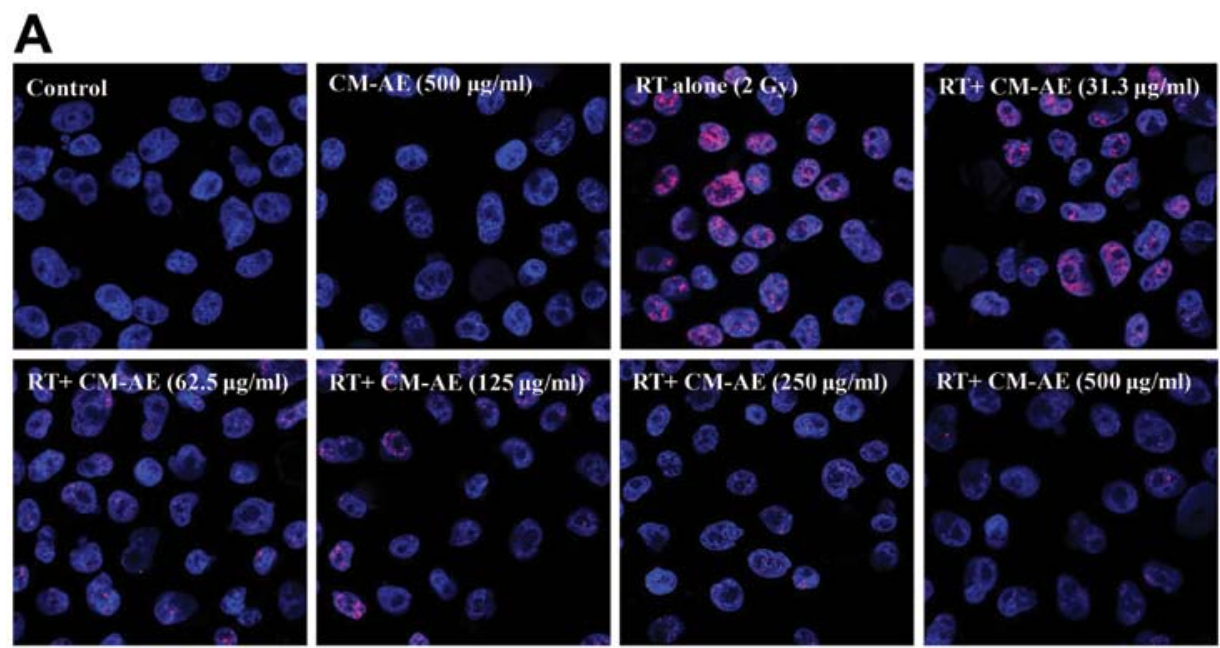

B

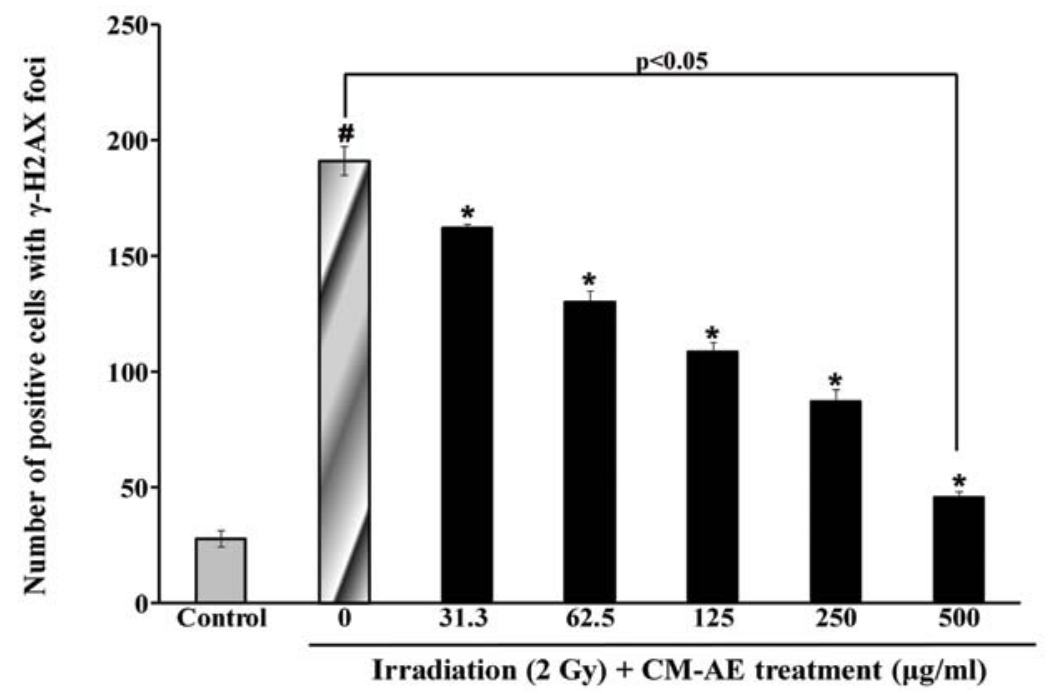

Figure 5. Reduced level of DNA double-strand breaks by CM-AE in ${ }^{137} \mathrm{Cs} \gamma$-radiation-exposed CHO-K1 cells. (A) Fluorescence images of phosphorylated H2AX (red) with Hoechst 33342 staining in nucleus (blue) and fluorescence intensities of phosphorylated H2AX in irradiated cells 45 min after irradiation (RT) in the absence or presence of CM-AE. (B) The number of positive cells with $\gamma$-H2AX foci was obtained from 3 independent experiments, and a total of 200 cells was analyzed. Data are the means $\pm \mathrm{SD}$ of triplicate samples of 3 independent experiments. ${ }^{\text {}} \mathrm{P}<0.05$ as compared to the non-irradiated control and $\mathrm{P}<0.05$ compared to irradiation alone.

reduction of plasmid DNA damage following treatment with cordycepin. These results provide evidence that the radioprotective effects of CM-AE against harmful chemicals and radiation are much more potent than those of cordycepin.

The exposure of cells to ionizing radiation can lead to the increased generation of ROS, including hydroxyl radicals $(\mathrm{OH})$, superoxide anions $\left(\mathrm{O}_{2}^{-}\right)$, singlet oxygen $\left({ }^{1} \mathrm{O}_{2}\right)$, and hydrogen peroxide $\left(\mathrm{H}_{2} \mathrm{O}_{2}\right)$, which are major determinants of cellular damage. Excessive ROS production leads to impaired intracellular ionic homeostasis by damaging cellular macromolecules, including DNA, proteins and lipids. Damaged DNA may lead to cell apoptosis or cancerization (37). Therefore, ROS-scavenging activity is also crucial for the development of radioprotectors (38). In a previous study, $C$. militaris was shown to reduce the intracellular ROS generation of human umbilical vein endothelial cells (HUVECs) exposed to high amounts of glucose (39) and cordycepin has also been reported to have the ability to scavenge ROS, and inhibit plateletderived growth factor (PDGF)-induced ROS generation (40). The present study revealed that CM-AE is a strong inhibitor of cellular ROS production in CHO-K1 cells irradiated with 2 Gy of ${ }^{137} \mathrm{Cs} \gamma$-radiation, while pre-treatment with cordycepin did not attenuate the ROS levels in the irradiated cells at the tested concentrations. Our results suggest that CM-AE effectively attenuated cellular ROS levels induced by radiation and that these effects were more potent to those induced by cordycepin.

DNA damage is the main event in radiation-induced cell death. ROS is a DNA damage agent producing a series of DNA lesions, including base damage, single- or doublestrand breaks, DNA-DNA or DNA-protein crosslinks and others. Double-strand breaks are the most important for cell killing (41). Since the amount of DNA damage caused by ionizing radiation correlates with the intensity of oxidative stress, there are several possible means to diminish macromolecular damage due to ionizing radiation. Several strategies have been shown to ameliorate radiation-induced damage, one of which is to reduce the amount of double-strand breaks, a critical source of radiation-induced damage, through antioxidant activity (32). In the present study, we investigated the comet parameters of $\gamma$-radiation-exposed $\mathrm{CHO}-\mathrm{K} 1$ cells, 
in which most of the strand breaks measured by the alkaline comet assay were single-strand breaks. The increased parameters induced by radiation were effectively prevented by a short-term incubation with CM-AE prior to irradiation. We further evaluated double-strand breaks in $\gamma$-radiation-exposed CHO-K1 cells through the frequency of $\gamma-\mathrm{H} 2 \mathrm{AX}$ foci. DNA DSBs are potentially damaging events in cells that are highly mutagenic when misrepaired and lethal if left unrepaired. Following DSB induction, phosphorylation mediated either by ataxia-telangiectasia-mutated, ataxia-telangiectasia-related or DNA-dependent protein kinase, occurs on serine 139 at the C-terminus of H2AX molecules flanking the DSBs in chromatin. The phosphorylated form of $\mathrm{H} 2 \mathrm{AX}$ is termed $\gamma$-H2AX (42). The appearance of $\gamma-\mathrm{H} 2 \mathrm{AX}$ in chromatin in the form of discrete nuclear foci, each of which represents a single double-strand break, can be detected immunocytochemically shortly after the induction of double-strand breaks (43). The increased number of $\gamma-\mathrm{H} 2 \mathrm{AX}$ foci induced by the radiation of CHO-K1 cells was also effectively prevented by shortterm incubation with CM-AE prior to irradiation. However, pre-treatment with cordycepin did not protect against cellular DNA damage, such as single- and double-strand breaks.

Nowadays, the major concern related to the development of radioprotectors in radiotherapy is an enhancement of the antitumor efficacy of radiation without causing unacceptable toxicity. Hence, the normal tissues should be protected against radiation injury to obtain optimal tumor control with a higher dose (44). Previous studies have reported that isolated compounds from $C$. militaris, such as polysaccharides or cordycepin show antitumor activity $(21,22)$, and it has also demonstrated that extracts obtained from $C$. militaris induce immunomodulation and tumor growth delay in mouse-derived breast cancer (23). Therefore, further studies are required to investigate potential candidate material from CM-AE of C. militaris as adjuvant materials for radiotherapy.

\section{Acknowledgements}

The present study was supported by the 2014 National R\&D Program through the Dong Nam Institute of Radiological and Medical Sciences (DIRAMS) funded by the Ministry of Education, Science and Technology (50493-2014).

\section{References}

1. Formenti SC and Demaria S: Systemic effects of local radiotherapy. Lancet Oncol 10: 718-726, 2009.

2. Kaanders JH and Ang KK: Early reactions as dose-limiting factors in radiotherapy. Semin Radiat Oncol 4: 55-67, 1994

3. Welsh JS, Limmer JP, Howard SP, Diamond D, Harari PM and Tome W: Precautions in the use of intensity-modulated radiation therapy. Technol Cancer Res Treat 4: 203-210, 2005.

4. Karbownik M and Reiter RJ: Antioxidative effects of melatonin in protection against cellular damage caused by ionizing radiation. Proc Soc Exp Biol Med 225: 9-22, 2000.

5. von Sonntag C: The chemical basis of radiation biology. Taylor \& Francis, London, pp9-30, 1987.

6. Löbrich $M$ and Jeggo PA: The impact of a negligent G2/M checkpoint on genomic instability and cancer induction. Nat Rev Cancer 7: 861-869, 2007.

7. van Gent DC, Hoeijmakers JH and Kanaar R: Chromosomal stability and the DNA double-stranded break connection. Nat Rev Genet 2: 196-206, 2001

8. Weiss JF and Landauer MR: Protection against ionizing radiation by antioxidant nutrients and phytochemicals. Toxicology 189: $1-20,2003$
9. Maurya DK, Devasagayam TP and Nair CK: Some novel approaches for radioprotection and the beneficial effect of natural products. Indian J Exp Biol 44: 93-114, 2006.

10. Hsu H, Yang JJ, Ho YH and Lin CC: Difference in the effects of radioprotection between aerial and root parts of Lycium chinense. J Ethnopharmacol 64: 101-108, 1999.

11. Devi PU and Ganasoundari A: Modulation of antioxidant enzymes by Ocimum sanctum and its role in protection against radiation injury. Indian J Exp Biol 37: 262-268, 1999.

12. Kamat JP, Boloor KK, Devasagayam TPA and Venkatachalam SR: Antioxidant properties of Asparagus racemosus against damage induced by gamma-radiation in rat liver mitochondria. J Ethnopharmacol 71: 425-435, 2000.

13. Zhang C, Zheng S, Zhang Y, Luo C and Guo C: The protective effective polysaccharide and C-phycocyanin from Spirulina platensis on acute radiation injury in mice. Acta Nutrimenta Sinica 18: 327-331, 1997.

14. Paterson RR: Cordyceps: a traditional Chinese medicine and another fungal therapeutic biofactory? Phytochemistry 69: 1469-1495, 2008.

15. Mizuno T: Medicinal effects and utilization of Cordyceps (Fr.) Link (Ascomycetes) and Isaria Fr. (Mitosporic Fungi) Chinese caterpillar fungi, 'Tochukaso' (Review). Int J Med Mushroom 1: 251-261, 1999.

16. Nag TB and Wang HX: Pharmacological actions of Cordyceps, a prized folk medicine. J Pharm Pharmacol 57: 1509-1519, 2005.

17. Cunningham KG, Hutchinson SA, Manson W and Spring FS: Cordycepin, a metabolic product from cultures of Cordyceps militaris (Linn.) Link. Part I. Isolation and characterisation. J Chem Soc 23: 2299-3200, 1951.

18. Ahn YJ, Park SJ, Lee SG, Shin SC and Choi DH: Cordycepin: selective growth inhibitor derived from liquid culture of Cordyceps militaris against Clostridium spp. J Agric Food Chem 48: 2744-2748, 2002.

19. Yoo HS, Shin JW, Cho JH, et al: Effects of Cordyceps militaris extract on angiogenesis and tumor growth. Acta Pharmacol Sin 25: 657-665, 2004

20. Won SY and Park EH: Anti-inflammatory and related pharmacological activities of cultured mycelia and fruiting bodies of Cordyceps militaris. J Ethnopharmacol 96: 555-561, 2005.

21. Yu HM, Wang BS, Huang SC and Duh PD: Comparison of protective effects between cultured Cordyceps militaris and natural Cordyceps sinesis against oxidative damage. J Agric Food Chem 54: 3132-3138, 2006.

22. Chen C, Luo SS, Li Y, Sun YJ and Zhang CK: Study on antioxidant activity of three Cordyceps sp. by chemiluminescence. Shanghai J Trad Chinese Med 38: 53-55, 2004.

23. Liu J, Yang S, Yang X, Chen Z and Li J: Anticarcinogenic effect and hormonal effect of Cordycceps militaris. Zhongguo Zhong Yao Za Zhi 22: 111-113, 1997 (In Chinese).

24. Wu WC, Hsiao JR, Lian YY, Lin CY and Huang BM: The apoptotic effect of cordycepin on human OEC-M1 oral cancer cell line. Cancer Chemother Pharmacol 60: 103-111, 2007.

25. Lin YW and Chiang BH: Anti-tumor activity of the fermentation broth of Cordyceps militaris cultured in the medium of Radix astragali. Proc Biochim 43: 244-250, 2008.

26. Jeong $\mathrm{MH}$, Lee CM, Lee SW, et al: Cordycepin-enriched Cordyceps militaris induces immunomodulation and tumor growth delay in mouse-derived breast cancer. Oncol Rep 30: 1996-2002, 2013.

27. Von Gadow A and Hansmann CF: Comparison of the antioxidant activity of aspalathin with that of other plant phenols of rooibos tea (Aspalathus linearis), alpha-tocopherol, BHT, and BHA. J Agric Food Chem 45: 632-638, 1997.

28. McCord JM and Fridovich I: Superoxide dismutase. An enzymic function for erythrocuprein (hemocuprein). J Biol Chem 244: 6049-6055, 1969.

29. Końca K, Lankoff A, Banasik A, et al: A cross-platform public domain PC image-analysis program for the comet assay. Mutat Res 534: 15-20, 2003.

30. Jeong MH, Yang KM, Jeong DH, et al: Protective activity of novel resveratrol analogue, HS-1793 against DNA damage in ${ }^{137} \mathrm{Cs}$ irradiated CHO-K1 cells. J Radiat Res 55: 464-475, 2013.

31. Londhe JS, Devasagayam TP, Foo LY and Ghaskadbi SS: Antioxidant activity of some polyphenol constituents of the medicinal plant Phyllanthus amarus Linn. Redox Rep 13: 199-207, 2008.

32. Hosseinimehr SJ: Trends in the development of radioprotective agents. Drug Discov Today 12: 794-805, 2007. 
33. Das SK, Masuda M, Sakurai A and Sakakibara M: Medicinal uses of the mushroom Cordyceps militaris: current state and prospects. Fitoterapia 81: 961-968, 2010.

34. Yu RM, Yang W, Song LY, Yan CY, Zhang Z and Zhao Y: Structural characterization and antioxidant activity of a polysaccharide from the fruiting bodies of cultured Cordyceps militaris. Carbohydr Polym 70: 430-436, 2007.

35. Wu F, Yan $\mathrm{H}$, Ma X, et al: Structural characterization and antioxidant activity of purified polysaccharide from cultured Cordyceps militaris. Afr J Microbiol Res 5: 2743-2751, 2011.

36. Hamburger M: Comment on comparison of protective effects between cultured Cordyceps militaris and natural Cordyceps sinensis against oxidative damage. J Agric Food Chem 55: 7213-7214, 2007.

37. Ogawa Y, Kobayashi T, Nishioka A, et al: Radiation-induced reactive oxygen species (ROS) formation prior to oxidative DNA damage in human peripheral T cells. Int J Mol Med 11: 149-152, 2003.

38. Gudkov SV, Shtarkman IN, Smirnova VS, Chernikov AV and Bruskov VI: Guanosine and inosine display antioxidant activity, protect DNA in vitro from oxidative damage induced by reactive oxygen species, and serve as radioprotectors in mice. Radiat Res 65: 538-545, 2006.
39. Chu HL, Chien JC and Duh PD: Protective effect of Cordyceps militaris against high glucose-induced oxidative stress in human umbilical vein endothelial cells. Food Chem 129: 871-876, 2011

40. Won KJ,Lee SC, Lee CK, et al: Cordycepin attenuates neointimal formation by inhibiting reactive oxygen species-mediated responses in vascular smooth muscle cells in rats. J Pharmacol Sci 109: 403-412, 2009.

41. Dizdaroglu M, Jaruga P, Birincioglu M and Rodriguez H: Free radical induced damage to DNA: mechanisms and measurement. Free Radic Biol Med 32: 1102-1115, 2002.

42. Rogakou EP, Pilch DR, Orr AH, et al: DNA double-stranded breaks induce histone $\mathrm{H} 2 \mathrm{AX}$ phosphorylation on serine 139 . J Biol Chem 273: 5858-5868, 1998.

43. Sedelnikova OA, Rogakou EP, Panyutin IG, et al: Quantitative detection of ${ }^{125}$ IdU-induced DNA double-strand breaks with $\gamma$-H2AX antibody. Radiat Res 158: 486-492, 2002.

44. Nair CK, Parida DK and Nomura T: Radioprotectors in radiotherapy. J Radiat Res 42: 21-37, 2001. 